\title{
Post-combustion Decarbonisation Processes
}

\author{
D.W. Bailey ${ }^{1}$ and P.H.M. Feron ${ }^{2}$ \\ 1 Alstom Power Turbo-Systems Technology Centre, Cambridge Road, Whetstone, Leicester, LE8 6LH - United Kingdom \\ 2 TNO Science and Industry, PO Box 342, 7300 AH Apeldoorn - The Netherlands \\ e-mail: david@aerospace.co.uk - paul.feron@tno.nl
}

Résumé - Capture post-combustion — Dans le cas de la capture post-combustion, le $\mathrm{CO}_{2}$ est séparé des gaz effluents. Ce procédé convient à la génération d'électricité conventionnelle et aux systèmes de conversion d'énergie. Les principaux procédés de conversion d'énergie et leurs performances sont décrits dans cet article. La technologie utilisée aujourd'hui, qui consiste à séparer le $\mathrm{CO}_{2}$ des effluents gazeux à l'aide de solvants, est présentée et les principaux procédés sont discutés. Plusieurs pistes de développement de ces procédés sont envisageables à l'avenir : accroissement de l'efficacité des procédés actuels, nouveaux procédés d'absorption avec de meilleurs solvants, utilisation de membranes, etc.

\begin{abstract}
Post-Combustion Decarbonisation Processes - Post-combustion decarbonisation processes are focused on the separation of $\mathrm{CO}_{2}$ from flue gases. The process route is ideally suitable for conventional power stations and energy conversion systems. The main energy conversion processes and components (steam boilers, gas turbines) are described and performances are given. The state-of-the-art process to separate $\mathrm{CO}_{2}$ from a flue gas, using the monoethanolamine solvent is discussed and performances of the leading processes are presented. Several development options are suggested such as improvement of available solvents and processes, novel absorption processes and membranes.
\end{abstract}




\section{BASIC PROCESS AND ENERGY CONVERSION DESCRIPTION}

The energy conversion systems for fossil fuels can broadly be classified by the technology variants adopted to produce power from coal and gas. An overview of coal and gas power generation is provided along with an introduction to the technical variants deployed.

\subsection{Coal Power Generation}

Coal fired boiler technology has developed rapidly over the last century, largely driven by industrialisation. The need for power and electricity has driven increases in the size of plant and its availability. During the last century, this has been achieved by increases in both steam temperature and pressure brought about through improved materials. During this time, power plant efficiency has increased from less than $10 \%$ at the turn of the century, through $20-35 \%$ during the middle of the century to above $45 \%$ for coal fired power stations at the end of the century (Fig. 1). As early as the 1970's, the first super-critical boiler with a capacity of $750 \mathrm{MW}$ was established.

\subsubsection{Pulverised Fuel (PF) Boilers}

In a typical PF boiler, coal is ground into fine particles before being injected (with air) through a number of burners into the bottom of a combustion chamber. The particles are burnt in suspension which releases heat that is transferred to water tubes in the walls of the combustion chamber. This process generates steam at both high pressure and temperature which is fed into a turbine and generator set to produce electricity. PF boilers are defined as "subcritical" if the steam is generated at a pressure below the critical pressure of 221.2 bar. At higher pressures, there is no distinct water and steam phase transition, and the boiler is defined as "supercritical". Supercritical technology offers the benefits of higher efficiency. In 2002, the 965 MW lignite fired power plant at Niederaussem (Fig. 2) went on stream with a net efficiency in excess of $45 \%$ (McMullan, 2004) and steam pressure and temperatures of $275 \mathrm{bar} / 580-600^{\circ} \mathrm{C}$.

Table 1 indicates the performance and emissions improvements from the upgrade to supercritical technology for the same sized plant.

TABLE 1

Performance of Subcritical vs. Supercritical (660MWe) (Bozzuto et al., 2001)

\begin{tabular}{l|c|c|c}
\hline & Units & Sub Critical PF & Super Critical PF \\
\hline Efficiency & $\% *$ & 40.8 & 43.6 \\
$\mathrm{CO}_{2}$ & $\mathrm{~kg} / \mathrm{MWhr}$ & 845 & 791 \\
$\mathrm{NO}_{x}$ & $\mathrm{~kg} / \mathrm{MWhr*}$ & 2.36 & 2.21 \\
$\mathrm{SO}_{2}$ & $\mathrm{~kg} / \mathrm{MWhr*}$ & 6.3 & 5.9 \\
Particulates & $\mathrm{kg} / \mathrm{MWhr**}$ & 0.158 & 0.148 \\
\hline
\end{tabular}

* LHV Basis (net).

** Flue gas clean up to 2001 World Bank Emissions Guidelines.

The goal of improving the efficiency of PF plant is continuing with the development of ultra supercritical boiler technologies. The goal of collaborative European research and technology projects such as AD700 and COST522 is to demonstrate that it is possible to operate plant with steam at a pressure of $375 \mathrm{bar}$ and at temperatures of $700 / 720^{\circ} \mathrm{C}$. This level of technology should lead to efficiencies in excess of $50 \%$.

\subsubsection{Fluidised Bed Combustion (FBC)}

Due to the increasing requirement for fuel flexibility (including the utilisation of renewable fuels such as biomass)

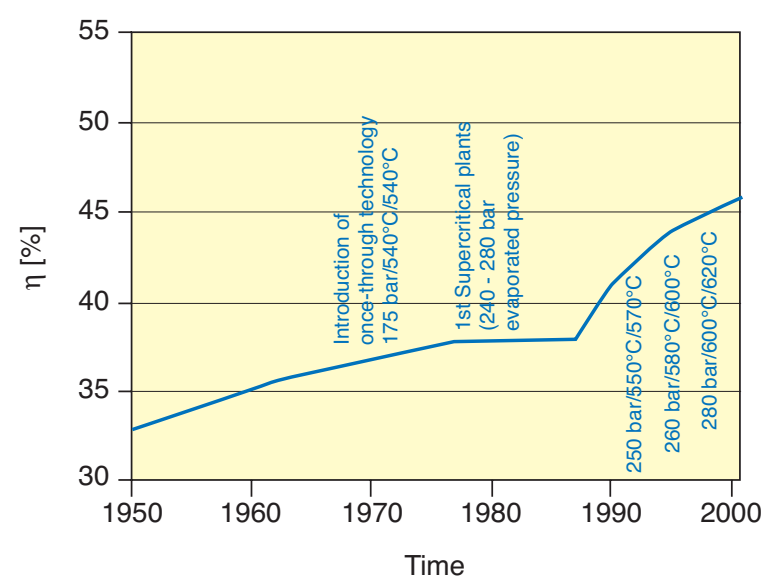

Figure 1

The efficiency of steam power plant in Europe (Stamatelopoulos et al., 2003).

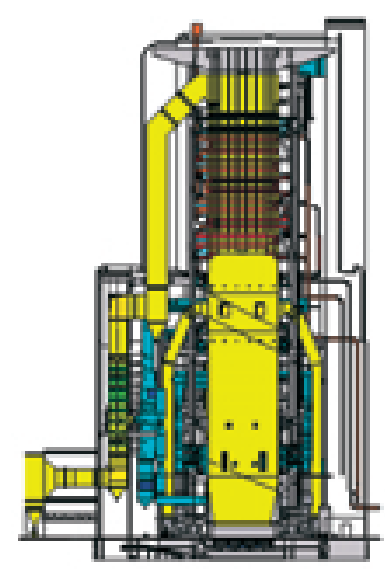

Figure 2

965 MW supercritical plant, Niederaussem, Germany (Owned by RWE Energie, boiler supplied by Alstom et al.). 
there has been a requirement for technologies capable of burning a variety of fuels efficiently and in an environmentally acceptable way. These fuels are often of a poor quality and are therefore available at low cost giving a plant capable of burning them and an operating cost benefit that can be substantial. Since PF technology depends on the combustion of very finely ground particles, Fluidised Bed Combustion (FBC) has been developed to meet these requirements.

In an FBC plant, combustion of the fuel (which can be in relatively large sizes of particle compared with PF plant) takes place within a fluidised bed suspended by an ascending air flow. The bed can be thought to behave like a fluid, with the speed of the ascending airflow sufficient to maintain the bed in a state of fluidisation and with a high level of mixing. The temperature of the bed is typically $850^{\circ} \mathrm{C}$ which is an optimum for low $\mathrm{NO}_{\mathrm{x}}$ formation and $\mathrm{SO}_{\mathrm{x}}$ capture by sorbents.

There are two main types of FBC plant, Bubbling Fluidised Bed Combustion (BFBC) and Circulating Fluidised Bed Combustion (CFBC) and both of these can be atmospheric (BFB and CFB in Figure 3) or pressurised (PBFB and $\mathrm{PCFB}$ in Figure 3).
A) BF B

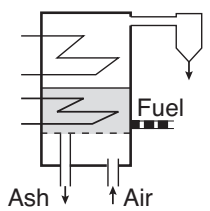

C) PBFB

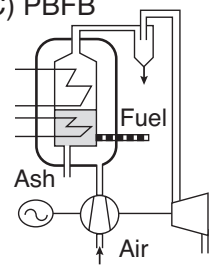

B) $\mathrm{CF} \mathrm{B}$

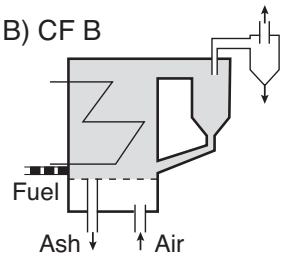

D) PCFB

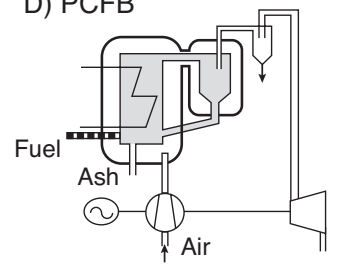

Figure 3

Illustration of the different types of fluidises bed power plants (IFRF Combustion File 87).

The Bubbling Fluidised Bed plant maintains a dense bed by setting the ascending airflow speed as just sufficient to keep the bed in a state of fluidisation and high mixedness, but also so that particles which are lifted out of the bed will still fall back into the bed. In contrast, with the Circulating Fluidised Bed plant, the air flow is higher through the bed thereby entraining solid particles from the bed which are carried upwards away from the bed surface so that the combustion chamber is filled by a turbulent cloud of particles. Solids leaving the combustion chamber are collected by a cyclone and re-injected into the system thereby reducing the amount of ash discharged with the flue gas.

The first major coal fired BFBC plant was installed in 1975 at Renfrew, Scotland. The largest BFBC power plant to date (to re-power a 350 MW PF plant) was built in Takehara, Japan. The trend, however, is for smaller industrial applications including co-firing of biomass and wastes with coal. Larger scale BFBC plant (150-300 MW) tends to be supplied for industrial application in paper and pulp mills. In contrast with BFBC, there are more than 1,200 CFBC plants installed with a capacity in excess of $65 \mathrm{GW}$ (including $900 \mathrm{CFBC}$ plant in China with an average size of $30 \mathrm{MW}$ ). Plant ranges in size from a few MW up to $300 \mathrm{MW}$. In 2002, Alstom supplied two 250 MWe CFB Boilers (Marchetti et al., 2003) to Choctaw Generation Limited Partnership located in Mississippi, USA. The plant is called Red Hills (Fig. 4) and commercial operation commenced in 2002.

Foster Wheeler has demonstrated a 297.5 MWe CFB running on eastern bituminous fuel operating at atmospheric pressure at Jacksonville, Duval County, Florida. Foster Wheeler worked with Jackson Electric Authority and US Department of Energy to develop the commercial demonstrator which received "Power Magazine's" 2002 Power Plant Award (Fig. 5).

Typical operating characteristics and emissions performance is presented in Table 2 (EIS, 2000). It can be seen that the levels of $\mathrm{NO}_{\mathrm{x}}$ and $\mathrm{SO}_{\mathrm{x}}$ emissions are substantially lower than those obtained from PF plant. The re-circulation of the solids in the CFB provides long particle residence times in the combustor thereby allowing combustion to take place at a lower temperature leading to lower $\mathrm{NO}_{\mathrm{x}}$ formation. The addition of limestone to the bed enables the removal of up to $98 \%$ of the $\mathrm{SO}_{2}$ and $\mathrm{SO}_{3}$ from the gases.

TABLE 2

Typical Operating Characteristics of the JEA Large Scale CFB (297.5 MWe)

\begin{tabular}{l|c|c}
\hline & Units & $\begin{array}{c}\text { JEA Large Scale CFB } \\
\text { Combustion } \\
\text { DemonstrationPlant }\end{array}$ \\
\hline Generating Capacity & $\mathrm{MW}$ & 297.5 \\
Power Production & $\mathrm{MWh} / \mathrm{yr}$ & $2,345,490$ \\
Efficiency (HHV) & $\%$ & 34 \\
$\mathrm{NO}_{\mathrm{x}}$ & $\mathrm{kg} / \mathrm{MWh}$ & 0.429 \\
$\mathrm{SO}_{2}$ & $\mathrm{~kg} / \mathrm{MWh}$ & 0.715 \\
Particulate Matter $_{\text {Volatile Organic Compounds }}$ & $\mathrm{kg} / \mathrm{MWh}$ & 0.052 \\
Carbon Monoxide $(\mathrm{CO})$ & $\mathrm{kg} / \mathrm{MWh}$ & 0.026 \\
Carbon Dioxide & $\mathrm{kg} / \mathrm{MWh}$ & 0.664 \\
\hline
\end{tabular}

The overall thermal efficiency of the CFB plant is rated at approximately $34 \%$. However, comparison with PF plant is generally performed on the basis of plant with SCR (Selective 


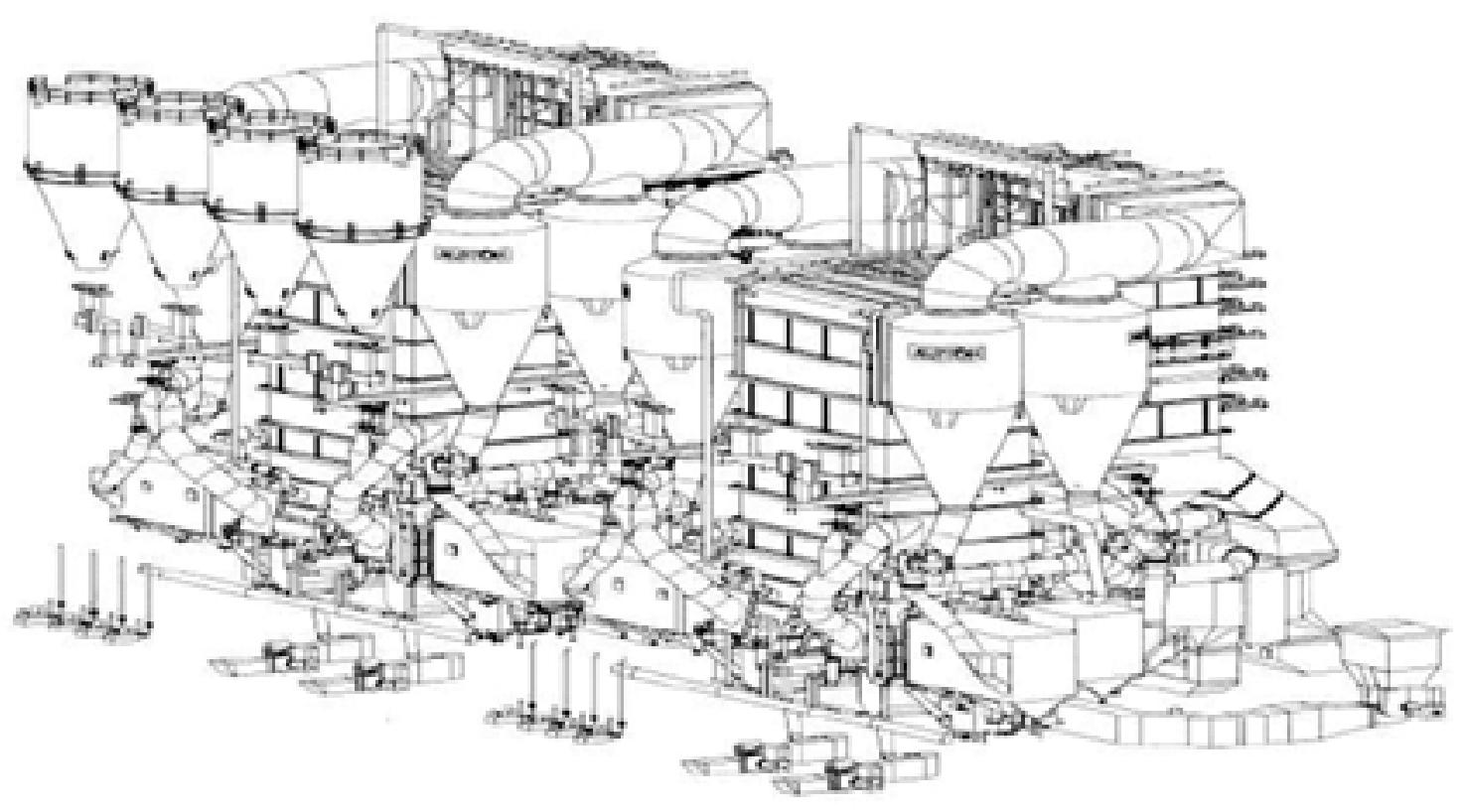

Figure 4

Red Hills $-2 \times 250$ MWe Circulating Fluidised Bed Boilers (Marchetti et al., 2003).

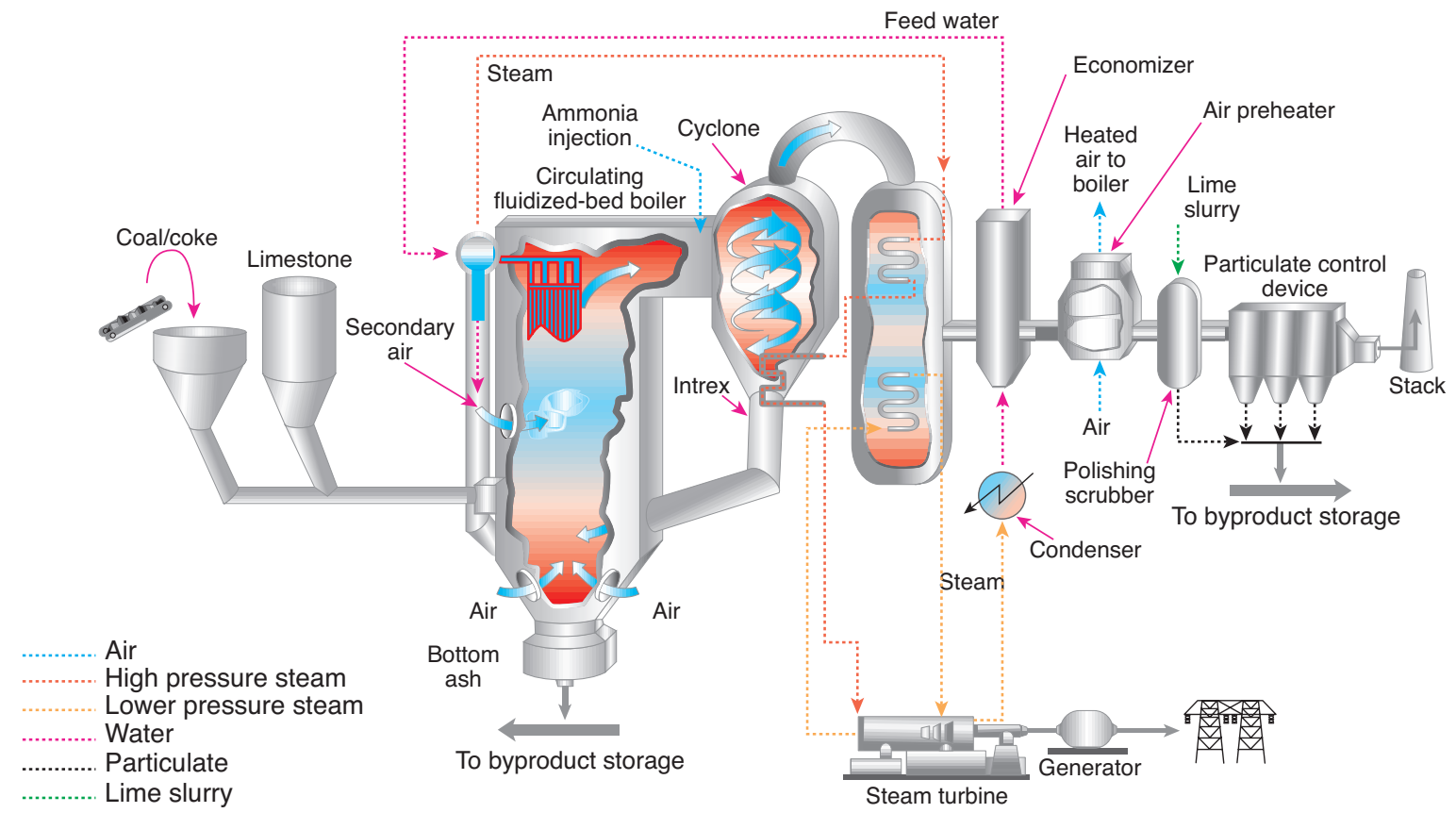

Figure 5

JEA large scale CFB combustion plant (owned by JEA, developed by Foster Wheeler). 
Catalytic Reduction) and FGD (Flue Gas Desulphurisation) technologies which reduce plant efficiency and increase capital and O\&M costs significantly.

\subsubsection{Pressurised Fluidised Bed Combustion (FBC)}

The pressurised FBC systems (PBFB and PCFB) involve the combustion of the solid fuel in a fluidised bed at pressure. Boiler tubes immersed in the fluidised bed generate steam which is expanded through a steam turbine to drive a generator. At the same time, the combustion gases are expanded through a gas turbine to drive another generator (Fig. 6). This results in higher cycle efficiency. However, since the combustion gases are limited to about $900^{\circ} \mathrm{C}$ the cycle cannot take account of the improved performance that could be obtained from the gas turbine at higher gas inlet temperatures.

The world's largest PFBC (360 MW) began commercial operations in July 2001. The plant was engineered and constructed by Ishikawajima Harima Heavy Industries (IHI) under licence from Alstom. IHI manufactured and erected the pressure vessel and PFBC system internals, fuel and ash handling equipment and the control system. Alstom supplied the heavy-duty gas turbine ( $75 \mathrm{MWe}$ operating at 13 bar and $850 \mathrm{C}$ ) that creates the fluidised bed and provides air for combustion, whilst Toshiba supplied the steam turbine ( $290 \mathrm{MWe}$ ). The gross thermal efficiency of the plant is reported (Yamamoto et al., 2003) to be $41.8 \%$ (net).
There are, however, several inherent problems with PFBC technology that have limited its application:

- Particles of ash in the hot exhaust gas from the boiler cause durability problems in the gas turbine.

- The gas turbine operates at low temperatures $\left(850^{\circ} \mathrm{C}\right)$ which reduces the cycle efficiency significantly.

- The availability of the PFBC plant is low due to the complexity of the configuration and difficulty with access to the boiler internals.

- The complex configurations are expensive and the resulting cost of electricity is not competitive.

\subsection{Gas Fired Power Plants}

Gas fired power plants are very popular today both because of reduced environmental concerns and cost. Gas fired plants are cheaper to operate than coal fired plants despite recent sharp rises in natural gas prices. A major reason for this is due to the high fuel efficiency achievable with the newer combined cycle gas power plants.

Combined cycle power plants (Fig. 7) generate electricity using two methods; the steam cycle and gas cycle. In the steam cycle, fuel is burned to boil water and create steam which turns a steam turbine driving a generator to create electricity. In the gas cycle, gas is burned in a gas turbine which directly turns a generator to create electricity. Combined cycle power plants operate by combining the gas

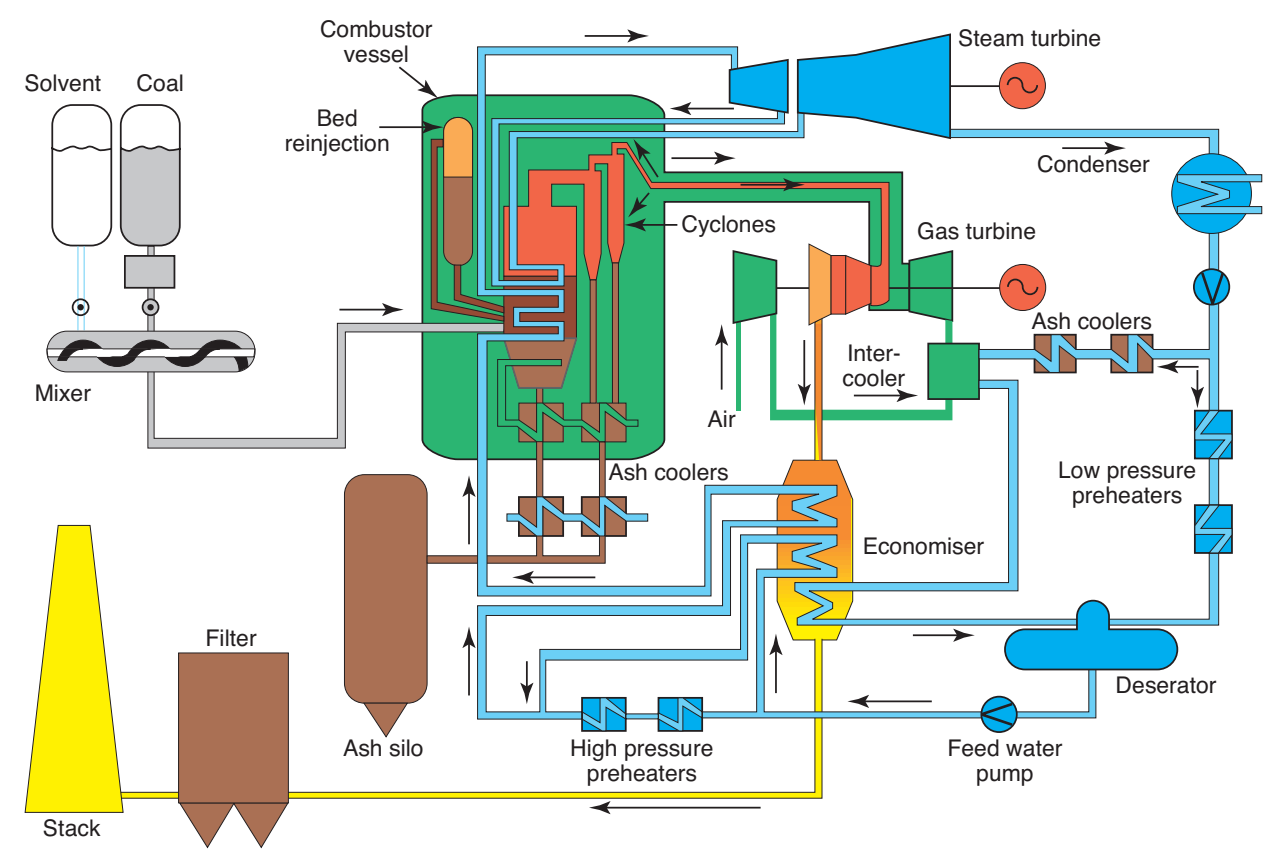

Figure 6

Schematic of a pressurised fluidised bed combustion concept (Bozzuto et al., 2001). 
How does a combined-cycle power plant work?

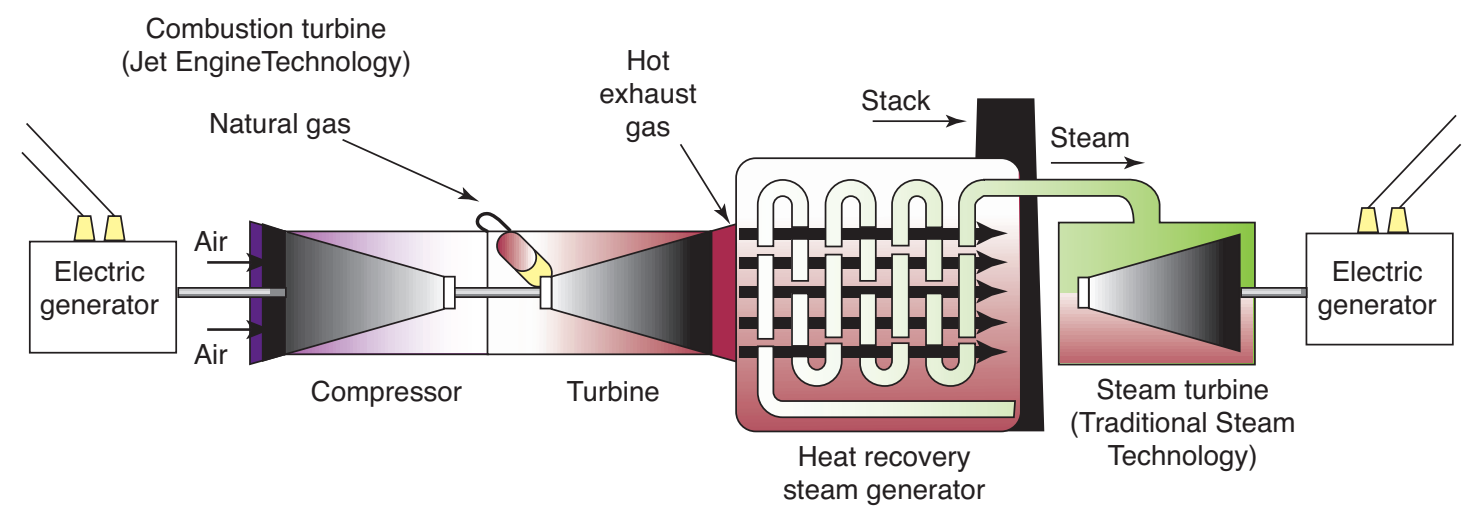

Figure 7

Operation of Combined Cycle Power Plant (FPL's new technology: the "repowered” Fort Myers plant).

cycle and the steam cycle for higher efficiency. The hot exhaust gases exiting the gas turbine are routed to the steam cycle and are used to heat or boil water. These exhaust gases typically carry away up to $70 \%$ of the energy in the fuel before it was burned, so recovering what otherwise would be wasted can double overall efficiency from $30 \%$ for a gas cycle only plant to $60 \%$ using the newest combined cycle technology.

Advancements in gas turbine technology have increased power and efficiency while decreasing emissions and lifecycle costs without sacrificing reliability. Retrofittable enhancements including advanced blading design, high temperature tolerant materials, sealing improvements, stateof-the-art component cooling and low emission combustion concepts have been incorporated in the newly developed gas turbines to ensure high performance. Operating gas fired power plants currently in use of this technology are meeting their combined cycle efficiency, power and emissions targets as well as the challenging and sometimes changing market demands.

One can see the latest performance of large industrial gas turbines developed by the major gas turbine manufacturers (Table 3, Figs 8, 9, 10, 11). A typical power output of the latest large industrial gas turbines is $180 \mathrm{MW}$ for $60 \mathrm{~Hz}$ and $270 \mathrm{MW}$ for $50 \mathrm{~Hz}$ application. The firing gas temperatures are between $1200^{\circ} \mathrm{C}$ and $1400^{\circ} \mathrm{C}$. The combined cycle efficiency of the gas-fired plants is 56-58\% depending on the manufacturer. These are values of combined cycle efficiency of the "F-class" gas turbine's technology. "G-class" gas turbines, which have a firing temperature of around $1500^{\circ} \mathrm{C}$ and achieve a combined cycle efficiency of about $59 \%$, have already been developed and in operation. "H-class" gas turbines, which apply "closed loop steam cooling" for turbine blades, are now under development. This new concept allows the turbine to fire at a higher temperature for increased performance, yet without increased combustion temperatures or

TABLE 3

Large Industrial Gas Turbine's performance (GT WORLD 2003-4 Spects)

\begin{tabular}{|c|c|c|c|c|c|c|c|c|}
\hline \multirow[b]{2}{*}{ GT TYPE - } & \multicolumn{2}{|c|}{ Alstom } & \multicolumn{2}{|c|}{ General electric } & \multicolumn{2}{|c|}{$\begin{array}{l}\text { Mitsubishi Heavy } \\
\text { Industries }\end{array}$} & \multicolumn{2}{|c|}{ Siemens W } \\
\hline & GT24B & GT26B & $7 \mathrm{FB}$ & $9 \mathrm{FB}$ & M501F & M701F & W501F & V94.3A \\
\hline Frequency $(\mathrm{Hz})$ & $60 \mathrm{~Hz}$ & $50 \mathrm{~Hz}$ & $60 \mathrm{~Hz}$ & $50 \mathrm{~Hz}$ & $60 \mathrm{~Hz}$ & $50 \mathrm{~Hz}$ & $60 \mathrm{~Hz}$ & $50 \mathrm{~Hz}$ \\
\hline GT power (MW) & 187 & 268.8 & 182 & 281 & 185 & 270 & 184 & 272 \\
\hline GT efficiency (\%) & 36.9 & 37.5 & 37.2 & 38.3 & 37 & 38.2 & 36.9 & 39.0 \\
\hline Combined cycle power (MW) & 276.7 & 410.3 & 280.3 & 412.9 & 279 & 399 & 274 & 390 \\
\hline Combined cycle efficiency (\%) & 56.4 & 57.8 & 57.3 & 57.7 & 56.7 & 57 & 55.5 & 57.6 \\
\hline Pressure ratio & 32 & 32 & 18.5 & 18.5 & 16 & 17 & 16 & 16.9 \\
\hline Gas firing temp $\left({ }^{\circ} \mathrm{C}\right)$ & 1280 & 1280 & 1371 & 1371 & 1400 & 1400 & 1350 & 1230 \\
\hline Exhaust mass flow (Kg/s) & 429 & 623 & 431.8 & 659 & 453 & 651 & 457 & 644 \\
\hline Exhaust gas temperature $\left({ }^{\circ} \mathrm{C}\right)$ & 611 & 612 & 593 & 620 & 607 & 586 & 594 & 585 \\
\hline
\end{tabular}


their resulting increased emission levels. Closed loop cooling also minimises parasitic extraction of compressor discharged air, thereby allowing more air to flow to the head-end of the combustor for fuel premixing. Those turbines are expected to achieve efficiency of $60 \%$ or more, and play a major role for high-efficient power generation in the next decade.

There is an increasing trend toward more combined cycle plants being commissioned in the world market for power generation. The combined cycle efficiency is strongly dependent on firing temperature. However the increase of the firing temperature seems to have reached a limit with the newly developed gas turbine engines. This saturation of the firing temperature comes from the fact that the flame temperature has to be kept below $1500^{\circ} \mathrm{C}$ to achieve low $\mathrm{NO}_{\mathrm{x}}$ emission $25 \mathrm{ppm}$ or less which comply within environmental regulations. The combustion control to stabilise the flame at lean fuel-to-air ratio is one of the most important challenges for all gas turbine manufacturers.

To use costly clean energy such as natural gas effectively, technological developments aimed at improving the efficiency of the combined cycle power generation have been vigorously promoted such as dry low $\mathrm{NO}_{\mathrm{x}}$ combustion, blade cooling technology, heat resistant materials, blade design as well as sealing improvements. The development of these key technologies for large industrial gas turbines can be made economical by using both the knowledge and experience acquired during earlier aeroengine developments. Aeroengines and their industrial derivatives, in contrast, are optimised for maximum cycle efficiency at higher cycle pressure ratios with lower gas turbine exit temperatures to minimise waste heat in the exhaust. It is not possible however in some fields to apply aeroengine's technologies to the industrial gas turbines due to the different sizes and requirements. Dry low $\mathrm{NO}_{\mathrm{x}}$ combustors for dual fuel use in the industrial gas turbines requires components that are much different from those for aeroengine's combustors. The industrial gas turbines have some advantage over the aeroengines with respect to the versatility of coolant, as for instance steam or air cooled by an external cooler. This advantage makes it possible to apply close loop steam cooling concepts to cool turbine blades in newly developed gas turbines. Similarly, there are other technological needs for the industrial gas turbine manufacturers that necessitate some deviation from technologies that may be appropriate to aeroengine's application.

The commercial development of combined-cycle power plants has proceeded in parallel with gas turbine development. Combined-cycles utilising the Brayton gas cycle and the Rankine steam cycle with air and water as working fluids achieve efficient, reliable, and economic power generation. Current commercially available power generation combinedcycle plants achieve net plant thermal efficiency typically of some 55-59\%. Further developments of gas turbine, high temperature materials and hot gas path, metal surface cooling technology show promise for near-term future power generation combined-cycle plants capable of reaching $60 \%$ or greater thermal efficiency. Fuel price escalation in the 1970s and 1980s further increased the need for more efficient

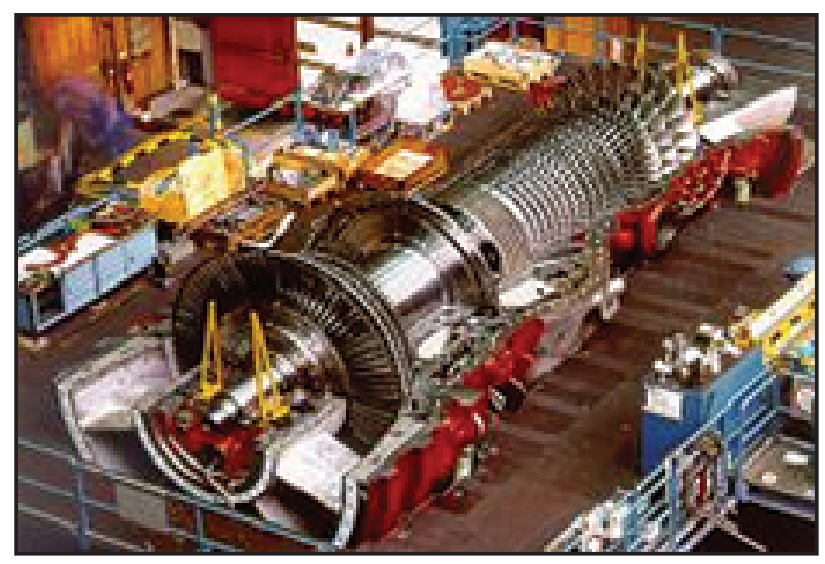

Figure 8

GT26B - $50 \mathrm{~Hz}$ (courtesy of Alstom Power generation).

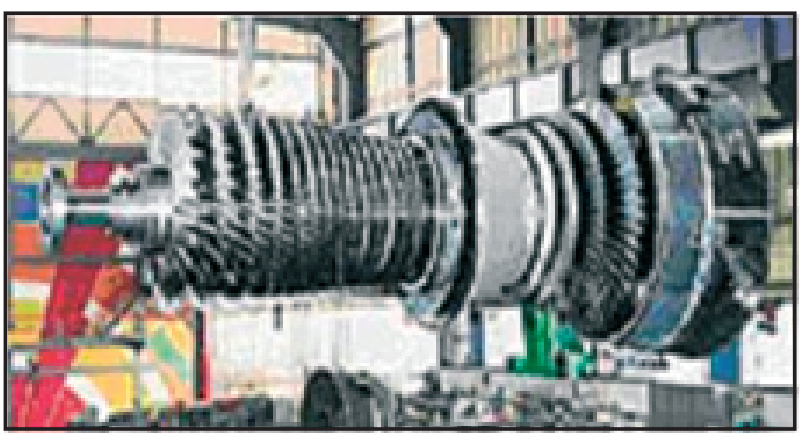

Figure 9

Siemens V94.3A rotor.

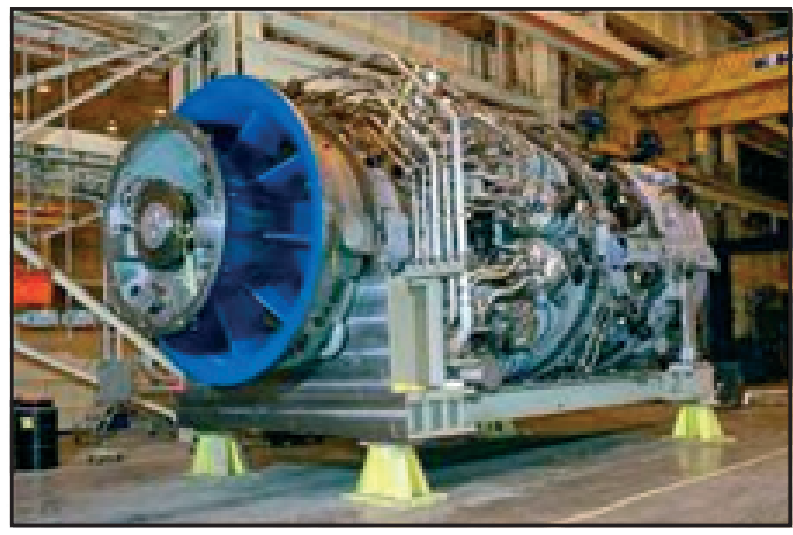

Figure 10

GE 7FB Series - $60 \mathrm{~Hz}$ (courtesy of General Electric Power Systems). 
power plants for base- and mid-rage duty. This led to the gas turbine designs in the late 1980s that were optimised specifically for combined cycle efficiency. Where simplecycle efficiency is the goal a high pressure ratio is desirable, whilst where combined-cycle efficiency is the objective more modest pressure ratios are selected. Firing temperature has a greater impact on combined-cycle efficiency than on simplecycle efficiency.

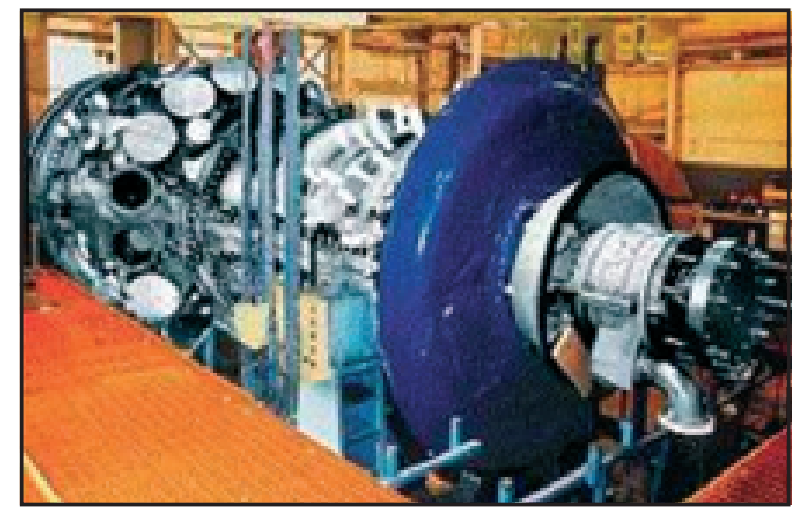

Figure 11

MHI M501G Series - 60Hz (Courtesy of Mitsubishi Heavy Industries Ltd).

The majority of combined-cycle plants are configured with open loop cooling of the turbine hot gas path and cooling air supplied from the compressor. Hot gas path components are in large part cooled by film cooling. As a result, there is significant exhaust gas temperature drop across the first stage nozzle, and significant "chargeable air" required to cool down the turbine stages. The drop in exhaust gas temperature across the first stage nozzle and the increase in chargeable cooling loss due to the increases in turbine firing temperature may diminish efficiency gains to the point of being uneconomical. The concept of closed loop steam cooling allows higher turbine firing temperature without increasing combustion temperature. This is because gas temperature drop across the first stage nozzle is significantly reduced. Another important benefit is the elimination of "chargeable cooling air" for the first and second stage rotating and stationary airfoils. This technology is expected to provide $2 \%$ thermal efficiency improvement. The application of ceramic hot gas path parts and coatings show promise for further future performance gains.

Steam cycle improvements that include increased steam pressure and temperature with supercritical steam cycles have near-term application. Current economic analysis indicates, however, that the thermodynamic gain associated with steam cycles that have steam temperatures and pressures above the current levels cannot be justified in most cases because of the added costs. As in the past, operating cost (fuel price) and the cost of new technology development will dictate the trend for increased combined-cycle efficiency.

\section{STATE-OF-THE-ART}

The state-of-the-art process to separate $\mathrm{CO}_{2}$ from a flue gas is a solvent process in which $\mathrm{CO}_{2}$ reacts with an absorption liquid. These chemical absorption processes are in general applicable to gas streams at both high and low overall process pressure, but which have a low $\mathrm{CO}_{2}$-partial pressure. They make use of the reversible nature of the chemical reaction, effected by a temperature difference. The heat of absorption is in the range $50-80 \mathrm{~kJ} / \mathrm{mole} \mathrm{CO}_{2}$. Figure 12 shows the equilibrium $\mathrm{CO}_{2}$-partial pressure of a chemical solvent and a physical solvent. The dependence between gas partial pressure and solvent loading is not linear one. At low partial pressure the loading of a chemical solvent will be higher.

The regeneration in a chemical solvent process is carried out at elevated temperatures $\left(100-140^{\circ} \mathrm{C}\right)$ and pressures not very much higher than the atmospheric pressure. This leads to a thermal energy penalty as a result of heating up of the solvent, the required desorption heat and the produced steam which acts as a strip gas.

Since power plant flue gases are generally at atmospheric pressure, $\mathrm{CO}_{2}$ partial pressure is very low. Also flue gas contains oxygen and other impurities; therefore an important aspect of an absorption process is in the proper choice of solvent for the given process duty. High $\mathrm{CO}_{2}$ loading and low heat of desorption energy are essential for atmospheric flue gas $\mathrm{CO}_{2}$ recovery. The solvents must also have low byproduct formation and low decomposition rates, to maintain solvent performance and to limit the amount of waste materials produced.

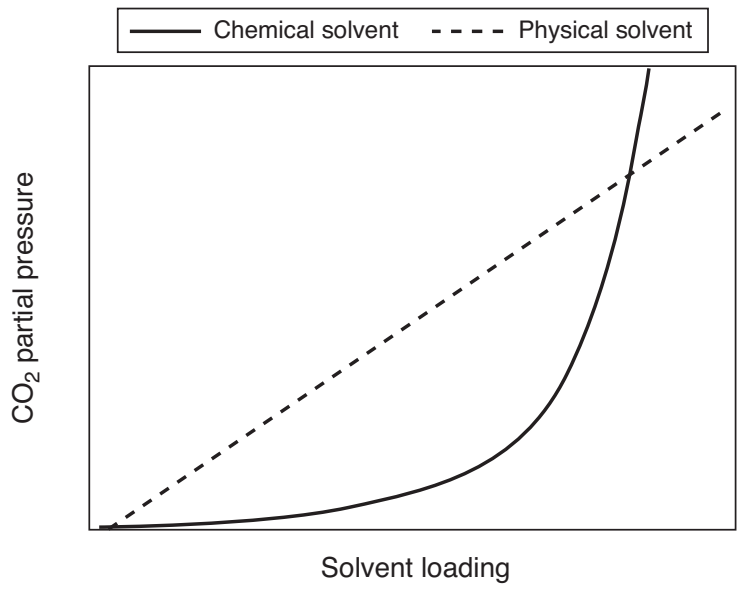

Figure 12

$\mathrm{CO}_{2}$ equilibrium partial pressure for a chemical solvent. 
Table 4 shows examples of commonly used chemical solvents. These solvents are primarily used for acid gas $\left(\mathrm{CO}_{2}\right.$, $\mathrm{H}_{2} \mathrm{~S}, \mathrm{COS}$ ) removal from natural gas and synthesis gas and to a limited extent also for $\mathrm{CO}_{2}$-removal from flue gases. They are often used as formulated solvents, containing dedicated mixtures to attain the separation task. Some chemical solvents also contain activators to promote the mass transfer in the absorption step.

TABLE 4

Commercially available chemical solvent processes

\begin{tabular}{l|l}
\hline Type of solvent & Example \\
\hline Primary amines & $\begin{array}{l}\text { Monoethanolamine (MEA), } \\
\text { Diglycolamine (DGA) }\end{array}$ \\
\hline Secondary amines & $\begin{array}{l}\text { Diethanolamine (DEA), } \\
\text { Diisopropanolamine (DIPA) }\end{array}$ \\
\hline Tertiary amines & $\begin{array}{l}\text { Methyldiethanolamine (MDEA), } \\
\text { Triethanolamine (TEA) }\end{array}$ \\
\hline Alkaline salt solutions & Potassium carbonate \\
\hline
\end{tabular}

Important items in the selection of chemical solvents are the $\mathrm{CO}_{2}$-loading capacity to result in low absorption liquid flow rates, the reaction rate as this will determine the size of the equipment and the heat requirement for regeneration, as this dominates the operating costs.

The loading capacity for chemical solvents is primarily dependent on the concentration of the active components and the achievable loading according to the thermodynamic equilibrium. For the range of alkanolamines the primary amines (MEA, DGA) will be more favourable in terms of reaction rates compared to secondary (DEA, DIPA), tertiary (MDEA) amines. However, achievable loadings and heat requirement for regeneration will be higher for primary amines. Table 5 gives an overview of the characteristics of commercially available absorption liquids.

\section{TABLE 5}

Overview of characteristics of commercially available chemical solvents (Chakma and Tontiwachwuthikul, 1999; Butwell et al., 1982; Versteeg et al., 1996)

\begin{tabular}{l|c|c|c|c|c}
\hline Solvent & MEA & DGA & DEA & DIPA & MDEA \\
\hline $\begin{array}{l}\text { Concentration } \\
(\% \text { mass })\end{array}$ & $<30$ & $<60$ & $<40$ & $<40$ & $<50$ \\
\hline $\begin{array}{l}\text { Typical loading } \\
(\text { mole/mole })\end{array}$ & 0.3 & 0.35 & $0.30-0.70$ & 0.45 & 0.45 \\
\hline $\begin{array}{l}\text { Heat of absorption } \\
\left(\mathrm{MJ} / \mathrm{kg} \text { of } \mathrm{CO}_{2}\right)\end{array}$ & 2.0 & 2.0 & 1.5 & 1.5 & 1.3 \\
\hline $\begin{array}{l}\text { Reaction rate at } 25^{\circ} \mathrm{C} \\
\left(\mathrm{m}^{3} / \mathrm{kmole} \cdot \mathrm{s}\right)\end{array}$ & 7600 & 4000 & 1500 & 400 & 5 \\
\hline
\end{tabular}

Monoethanolamine (MEA) is the state-of-the-art solvent (Chapel et al., 1999; Barchas, 1992) for capture from flue gas. However, novel solvents with lower energy consumption for regeneration are currently becoming available (Mimura et al., 2001; Sartori et al., 1994).

The following three solvent processes are commercially available for $\mathrm{CO}_{2}$ capture in post-combustion systems:

- The Kerr-McGee/ABB Lummus Crest Process (Barchas and Davis, 1992). This process uses a 15 to $20 \mathrm{wt} \%$ aqueous MEA solution. The largest capacity experienced for this process is $800 \mathrm{t} /$ day of $\mathrm{CO}_{2}$ utilising two parallel trains (Arnold et al., 1982).

- The Fluor Daniel ${ }^{\circledR}$ ECONAMINE ${ }^{\mathrm{TM}}$ Process (Sander and Mariz, 1992, Chapel et al.,1999). This process was acquired by Fluor Daniel Inc. from Dow Chemical Company in 1989. It is a MEA based process (30 wt\% aqueous solution) with an inhibitor to resist carbon steel corrosion and is specifically tailored for oxygen containing gas streams. It has been used in many plants worldwide recovering up to $320 \mathrm{t} /$ day of $\mathrm{CO}_{2}$ in a single train for use in beverage and urea production.

- The Kansai Electric Power Co., Mitsubishi Heavy Industries, Ltd. Process (Mimura et al., 2000). The process is based upon sterically hindered amines and already three solvents (KS-1, KS-2 and KS-3) have been developed. KS-1 was commercialised in a urea production application in Malaysia (200 t/day $\left.\mathrm{CO}_{2}\right)$ in 1999. The major benefits in this process are low heat requirements for regeneration, low amine losses and low solvent degradation without the use of inhibitors or additives.

\section{COMPONENT AND PROCESS CONSIDERATIONS}

The typical flow sheet of $\mathrm{CO}_{2}$ recovery using chemical solvents is shown in Figure 13.

After cooling the flue gas, it is brought into contact with the solvent in the absorber. A blower is required to pump the gas through the absorber. At temperatures typically between 40 and $60^{\circ} \mathrm{C}, \mathrm{CO}_{2}$ is then bound by the chemical solvent in the absorber. After passing through the absorber the flue gas undergoes a water wash section to balance water in the system and to remove any solvent droplets or solvent vapour carried over and then leaves the absorber. It is possible to reduce $\mathrm{CO}_{2}$ concentration in the feed gas down to very low values, as a result of the chemical reaction in the solvent, but with lower exit concentrations tending to increase the height of the absorption vessel. The "rich" solvent, which contains the chemically bound $\mathrm{CO}_{2}$ is then pumped to the top of a stripper, via a heat exchanger. The regeneration of the chemical solvent is carried out in the stripper at elevated temperatures $\left(100-140^{\circ} \mathrm{C}\right)$ and pressures not very much higher than atmospheric pressure. Heat is supplied to the 


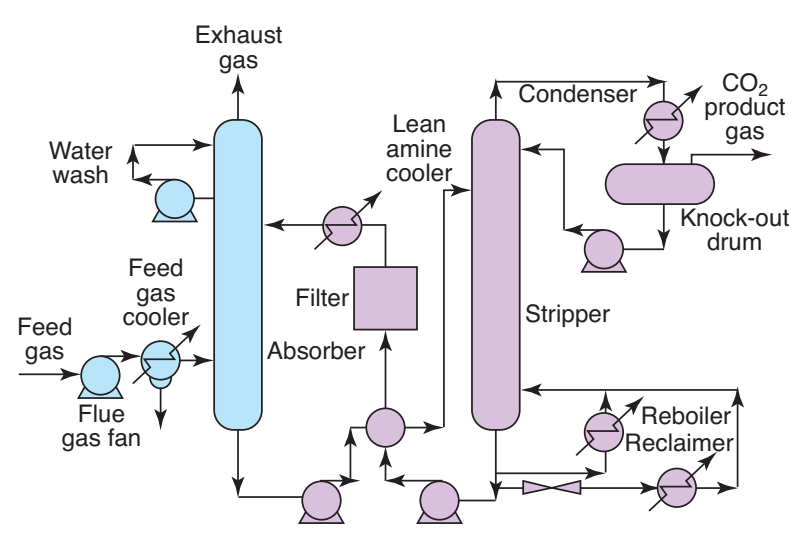

Figure 13

Process flow diagram for $\mathrm{CO}_{2}$ recovery from flue gas with chemical solvent (MEA).

reboiler to maintain the regeneration conditions. This leads to a thermal energy penalty as a result of heating up the solvent, providing the required desorption heat for removing the chemically bound $\mathrm{CO}_{2}$ and for steam production which acts as a stripping gas. Steam is recovered in the condenser and fed back to the stripper, whereas the $\mathrm{CO}_{2}$ product gas leaves the condenser. The $\mathrm{CO}_{2}$-product is a relatively pure (>99\%) product, with water vapour being the main other component. Due to the selective nature of the chemical absorption process, the concentration of inert gases is low. The $\mathrm{CO}_{2}-$ product might contain trace components, e.g. volatile solvent decomposition products or components carried over from the flue gas. A further $\mathrm{CO}_{2}$ purification step makes it possible to bring the $\mathrm{CO}_{2}$-quality up to food-grade standard. The "lean" solvent, containing far less $\mathrm{CO}_{2}$ is then pumped back to the absorber via the lean-rich heat exchanger and a cooler to bring it down to the absorber temperature level. It is possible to reduce $\mathrm{CO}_{2}$ concentration in purified gas down to negligible values, as a result of the chemical reaction in the solvent.

Solvent degradation, either by the continuous thermal cycling solvent or induced by the oxygen present in the flue gases is a major concern in $\mathrm{CO}_{2}$ capture from flue gases. It will also influence the corrosion rates in the reboiler. The common method to deal with this is to incorporated oxygen scavengers and corrosion inhibitors. Also in some part of the plant the use of stainless steel is recommended to avoid corrosion. In addition to this, the use of carbon beds and filters will control these operational problems. Acid components present in the flue gas, like $\mathrm{SO}_{2}$, will react with the amines in way similar to $\mathrm{CO}_{2}$. The $\mathrm{CO}_{2}$ carrying capacity of the solution can be restored by adding an alkaline component $e$.g. sodium hydroxide. This results in a heat stable salt. The amine can be recovered thermally in the reclaimer. It is also possible to reduce the concentration of acidic components in the flue gas down to levels in which the effect on the $\mathrm{CO}_{2}$-solvent is limited.

The following parameters influence the techno-economic performance to a large extent:

\section{Flue Gas Characteristics}

The flue gas characteristics, such as $\mathrm{CO}_{2}$-content, flow rate and impurities, will determine the performance of a capture process. These characteristics are more or less determined by the plant type. The $\mathrm{CO}_{2}$-content of flue gases from coal fired power plants will be between 12 and $15 \%$, whereas the levels for a gas fired combined cycle will be between 3 and $4 \%$, in both cases at atmospheric pressure. A higher $\mathrm{CO}_{2}$ content results in a higher driving force for absorption and therefore a smaller size column at a given $\mathrm{CO}_{2}$ production capacity.

The flue gas flow rate will determine the size of the absorber and the absorber represents a sizeable contribution to the overall cost because of the high volume gas flows. Also any flue gas pre-treatment, e.g. cooling of the flue gas or additional removal of impurities $\left(\mathrm{SO}_{2}, \mathrm{NO}_{\mathrm{x}}\right.$, dust), will involve relatively big and costly equipment. The flue gas flow rate will also impact the operational costs through the power consumption of the blower required for the pumping the flue gas through the absorber.

\section{Fractional $\mathrm{CO}_{2}$-Removal}

The fractional removal of $\mathrm{CO}_{2}$ is a parameter which can be chosen freely in principle. However, in practice there might by technical or economical limitations. Typical $\mathrm{CO}_{2}$ recoveries currently considered are between 80 and $95 \%$. The exact value is ideally the result of an optimisation. High recoveries will be desired to realise a large impact of the capture process on the $\mathrm{CO}_{2}$-emission, but the cost associated with this will also increase. A higher recovery will lead to a taller absorption column and higher energy penalties because more $\mathrm{CO}_{2}$ needs to be removed. In practice it seems this optimisation is rarely made.

\section{Solvent Type}

The solvent type and characteristics, particularly the amount of $\mathrm{CO}_{2}$ it can absorb, are the determining factors in the process performance. The solvent flow rate will determine the size of most equipment apart from the absorber and contributes to the process energy requirement. In flue gas applications for a given solvent, the flow rate will be primarily determined by the required $\mathrm{CO}_{2}$ production capacity. For the commonly used solvents there is only small influence of the $\mathrm{CO}_{2}$-content. The solvent consumption should be low to avoid high costs. This means that the vapour pressure has to be low, but also that the solvent must be stable under the typical operating conditions. Thermal stability and oxidative stability are important in this respect, also because they might enhance corrosion. Normally, the solvent used is a formulated mixture to which also corrosion inhibitors and oxygen scavengers are added. 


\section{Utilities Requirement}

The main utilities requirement in an absorption process are energy, both heat and electricity, and cooling. The energy requirement of the process is the sum of the thermal energy needed to regenerate the solvents and the electrical energy required to operate liquid pumps, the flue gas fan and the $\mathrm{CO}_{2}$-compressor. The thermal energy required to regenerate the solvent can be extracted from the steam cycle in the power plant or brought in from a separate unit. In a power plant this will lead to loss in power production, which is obviously not desired. Cooling is needed to bring the flue gas and solvent temperatures down to temperature levels required for efficient absorption of $\mathrm{CO}_{2}$. Also the product from the stripper will require cooling to recover steam from the stripping process. Finally, the $\mathrm{CO}_{2}$-compressor will need cooling between separate stages. Smaller utilities requirements are in the area of solvent chemicals, solvent additives and carbon beds to purify the solvents.

A comparison between the three commercially available processes on a number of key performance parameters is presented in Table 6.

\section{DEVELOPMENT OPTIONS}

\subsection{Improvement of Available Processes}

Vendors have been continuously improving their processes over the last decade. In a recent study carried out by IEA (IEA GHG R\&D, 2004), the heat requirement for solvent regeneration in the Fluor Daniel process was further reduced by a split flow arrangement, absorber intercooling, and an improved solvent formulation. The use of flash step after the stripper was also found to be advantageous. A study carried out by the CCP (Chinn et al., 2004) also indicated that using a flash step after the stripper was advantageous in reducing the thermal energy requirement. The study also claimed cost reductions through the avoidance of flue gas cooling and sending the hot flue gases directly into the absorber. Also the Mitsubishi process is undergoing continuous improvements, resulting in a lower energy consumption compared to MEA-based processes. In addition to this, the CCP study has resulted in cost reductions by a detailed analysis of the design, equipment and materials used in capture processes.

\subsection{Integration into Power Plants}

The integration of the capture process into a power plant is an area which has received little attention. A power plant with post-combustion $\mathrm{CO}_{2}$-capture using solvent technology can be looked upon as a cogeneration plant where the heatcustomer is the $\mathrm{CO}_{2}$-production plant. Hence, integration methods used in cogeneration plants are equally applicable in $\mathrm{CO}_{2}$-capture. Mitsubishi Heavy Industries has looked into the integration in more detail (Mimura et al., 1995, Mimura et al., 1997) and proposed the re-use of heat in the overhead condenser in the stripper to preheat boiler feed water. Also the steam condensate coming from the reboiler could be reused in the boiler feed water deaerator.

TABLE 6

Performance of processes for $\mathrm{CO}_{2}$-separation from flue gas

\begin{tabular}{|c|c|c|c|}
\hline & $\begin{array}{c}\text { Kerr-McGee/ABB } \\
\text { Lummus Crest Process } \\
\text { (Company brochure, 1992) }\end{array}$ & $\begin{array}{c}\text { ECONAMINE }^{\mathrm{TM}} \\
\text { (Sander and Mariz, 1992; } \\
\text { Chapel } \text { et al., 1999) }\end{array}$ & $\begin{array}{l}\text { Mitsubishi KS-1 } \\
\text { (Mimura et al., } \\
\text { 1997, 1999) }\end{array}$ \\
\hline Licenser & ABB Lummus & Fluor Daniel & $\begin{array}{c}\text { Kansai Electric Power and } \\
\text { Mitsubishi Heavy Industries. Ltd. }\end{array}$ \\
\hline $\begin{array}{l}\text { Steam for solvent } \\
\text { regeneration ( } 3 \text { Bar. G.) }\end{array}$ & $\begin{array}{c}2.3-3.0 \mathrm{t} / \mathrm{t} \mathrm{CO}_{2} \\
\left(5-6.5 \mathrm{GJ} / \mathrm{tCO}_{2}\right)\end{array}$ & $\begin{array}{c}1.94 \mathrm{t} / \mathrm{t} \mathrm{CO} \\
\left(4.2 \mathrm{GJ} / \mathrm{t} \mathrm{CO}_{2}\right)\end{array}$ & $\begin{array}{c}1.5 \mathrm{t} / \mathrm{t} \mathrm{CO} \\
\left(3.2 \mathrm{GJ} / \mathrm{t} \mathrm{CO}_{2}\right)\end{array}$ \\
\hline Solvent flow rate & $\begin{array}{c}25 \mathrm{~m}^{3} / \mathrm{t} \mathrm{CO}_{2} \\
\text { (estimated) }\end{array}$ & $17 \mathrm{~m}^{3} / \mathrm{t} \mathrm{CO}_{2}$ & $\begin{array}{l}11 \mathrm{~m}^{3} / \mathrm{tCO}_{2} \\
\text { (estimated) }\end{array}$ \\
\hline $\begin{array}{l}\text { Electricity for fans } \\
\text { and pumps }\end{array}$ & $100-300 \mathrm{kWh} / \mathrm{t} \mathrm{CO}_{2}$ & $\begin{array}{c}110 \mathrm{kWh} / \mathrm{t} \mathrm{CO}{ }_{2}(\mathrm{GTCC}) \\
40 \mathrm{kWh} / \mathrm{t} \mathrm{CO}(\mathrm{PCF})\end{array}$ & $\begin{array}{c}11 \mathrm{kWh} / \mathrm{t} \mathrm{CO}_{2} \\
(\mathrm{PCF})\end{array}$ \\
\hline Cooling Water & $75-150 \mathrm{~m}^{3} / \mathrm{tCO}_{2}$ & $\begin{array}{c}165 \mathrm{~m}^{3} / \mathrm{t} \mathrm{CO} \\
\left(\Delta \mathrm{T}=10^{\circ} \mathrm{C}\right)\end{array}$ & $\begin{array}{l}150 \mathrm{~m}^{3} / \mathrm{tCO}_{2} \\
\text { (estimated) }\end{array}$ \\
\hline Solvent consumption & $0.45 \mathrm{~kg} / \mathrm{t} \mathrm{CO}$ & $1.5-2.0 \mathrm{~kg} / \mathrm{t} \mathrm{CO}$ & $0.35 \mathrm{~kg} / \mathrm{t} \mathrm{CO}$ \\
\hline Activated carbon consumption & Not available & $0.075 \mathrm{~kg} / \mathrm{t} \mathrm{CO}$ & Not available \\
\hline $\mathrm{SO}_{2}$-tolerance & $<100 \mathrm{ppm}$ & $<10 \mathrm{ppm}$ & $<10 \mathrm{ppm}$ \\
\hline
\end{tabular}




\subsection{Novel Absorption Process}

Various novel solvents are being investigated, with the object of achieving a reduced energy use for solvent regeneration. This has the following contributions:

- The energy required to break the binding between $\mathrm{CO}_{2}$ and the active component in the solvent. Reducing this energy requirement can be achieved by using amines with a lower binding energy for $\mathrm{CO}_{2}$. This has to be balanced with the reaction rates, which might be lower. This will then lead to a larger absorber.

- The evaporation enthalpy for the stripping steam which leaves the stripper together with the $\mathrm{CO}_{2}$. The amount of water vapour leaving the stripper is controlled by the operating conditions of the stripper and the type of solvent.

- The heat required for the bringing the solvent up to the reboiler temperature. A solvent with a high cyclic loading will lead to a lower heat requirement, as there is less solvent to heat up.

Examples of current developments are:

- Dedicated amine mixtures (Chakma, 1995; Chakma and Tontiwachwuthikul, 1999). The development is aimed at lowering the $\mathrm{CO}_{2}$-binding energy and hence the overall energy consumption whilst keeping the reaction rates at economically attractive levels.

- Use of ammonia for $\mathrm{CO}_{2}$-capture (Xian-Yu Zheng et al., 2003). The use of ammonia will result in a high loading of the solvent and provides a product (urea) which could be used as a fertiliser.

- Promoted aqueous potassium carbonate (Cullinane and Rochelle, 2003). This solvent mixture combines the fast reaction of $\mathrm{CO}_{2}$ with piperazine with the low binding energy for carbonates.

- Non-aqueous solvents (Leites, 1998). The use of nonaqueous solvents has the benefit that the energy for the production of steam is not needed.

- Amino-acid salt solutions (Erga et al., 1995; Feron and ten Asbroek, 2004). Amino-acids are alternatives to amines for $\mathrm{CO}_{2}$. They are salt solutions with lower vapour pressure and some of them have a high stability towards oxygen present in the flue gas.

- Di-amines (Aresta and Dibenedetto, 2003). Components with more than one amine group will be able to bind more $\mathrm{CO}_{2}$ molecules. This results in a lower solvent flow and hence reduced energy requirement for regeneration.

- Use of ionic liquids (Baltus et al., 2005). Ionic liquids have no vapour pressure and are generally regarded as "green solvents" for many separations. The potential benefit for $\mathrm{CO}_{2}$ capture is that there is no thermal energy required for the production of stripping steam.

Beside novel solvents, novel process designs are also currently becoming available (Leites et al., 2003). As already mentioned, the use of a split flow system can lead to reductions in the energy consumption (IEA GHG R\&D 2004). In such a system there are two liquid flows: one for the bulk removal of $\mathrm{CO}_{2}$, which undergoes a partial regeneration (requiring less heat) and one for the removal down to outlet specification, which requires a deeper regeneration.

Research is also being carried out to improve upon the existing practices. One of the areas is the increase of concentration levels of aqueous MEA solution (Aboudheir et al., 2003). Also methods to prevent oxidative degradation of MEA by deoxygenation of the solvent solutions are being investigated (Chakravarti et al., 2001). In addition to this the catalytic removal of oxygen in flue gases from coal firing has been suggested (Nsakala et al., 2001) to enable operation of promising solvents sensitive to oxygen. This could enable the use of MDEA as a solvent for $\mathrm{CO}_{2}$ capture from flue gases.

\subsection{Membranes}

Membrane processes are used commercially for $\mathrm{CO}_{2}$ removal from natural gas at high pressure and at high $\mathrm{CO}_{2}$ concentration. In flue gases, the low $\mathrm{CO}_{2}$ partial pressure provides a low driving force for gas separation. Therefore, the flue gas needs to be compressed to pressure levels at which there is a high enough driving force for $\mathrm{CO}_{2}$ (total pressure at least $10 \mathrm{bar}$ ). As a consequence, the removal of carbon dioxide using commercially available polymeric gas separation membranes results in higher energy penalties on the power generation compared to a standard chemical absorption process (Herzog et al., 1991; Van der Sluijs et al., 1992 and Feron, 1994). Also, the maximum percentage of $\mathrm{CO}_{2}$ removed is lower than for a standard chemical absorption processes. Improvements can be made if more selective membranes become available, such as facilitated transport membranes. Facilitated transport membranes rely on the formation of complexes or reversible chemical reactions of components present in a gas stream with compounds present in the membrane. These complexes or reaction products are then transported through the membrane. Although solution and diffusion still play a role in the transport mechanism, the essential element is the specific chemical interaction of a gas component with a compound in the membrane, the so-called carrier. Like other pressure driven membrane processes, the driving force for the separation comes from a difference in partial pressure of the component to be transported. An important class of facilitated transport membranes is the so-called supported liquid membrane in which the carrier is dissolved into a liquid which is contained in a membrane. For $\mathrm{CO}_{2}^{-}$ separations, carbonates, amines and molten salt hydrates have been suggested as carriers (Feron, 1992). Porous membranes and ion-exchange membranes have been employed as the support. Until now, supported liquid membranes have only been studied on a laboratory scale. 
Practical problems associated with supported liquid membranes are membrane stability and liquid volatility. Furthermore, the selectivity for a gas decreases with increasing partial pressure on the feed side. This is a result of saturation of the carrier in the liquid, which limits the $\mathrm{CO}_{2}$-transfer. Also, as the total feed pressure is increased, the permeation of unwanted components is increased. This also results in a decrease in selectivity. Finally, selectivity is reduced by a reduction in membrane thickness. Recent development work has focused on the following technological options:

- Amine containing membranes (Teramoto et al., 1996);

- Potassium carbonate containing polymer gel membranes (Okabe et al., 2003);

- Potassium carbonate-glycerol containing membranes (Chen et al., 1999);

- Dendrimer containing membranes (Kovalli and Sirkar, 2001);

- Poly-electrolyte membranes (Quinn and Laciak, 1997).

\subsection{Other Processes}

Other relevant development options, i.e. membrane contactors and high temperature sorbents, are discussed in the chapter on novel capture processes.

\section{REFERENCES}

Aboudheir, A., Tontiwachwuthikul, P., Chakma, A. and Idem, R. (2003) Kinetics of the Reactive Absorption of Carbon Dioxide in High $\mathrm{CO}_{2}$-Loaded, Concentrated Aqueuous Monoethanolamine Solutions. Chemical Engineering Science, 58, 5195-5210.

Audus, H. (1998) Leading Options for the Capture of $\mathrm{CO}_{2}$ at Power Stations, Greenhouse Gas Control Technologies. Riemer, P., Eliasson, B., Wokaun, A. (eds.), Elsevier Science, Ltd., Kidlington, United Kingdom, 91-96.

Aresta, M. and Dibenedetto, A. (2003) New Amines for the Reversible Absorption of Carbon Dioxide from Gas Mixtures, Greenhouse Gas Control Technologies, Vol. II, J. Gale, Y. Kaya, Elsevier Science, Ltd., Kidlington, United Kingdom, 1599-1602.

Arnold, D.S., Barrett, D.A. and Isom, R.H. (1982) $\mathrm{CO}_{2}$ can be Produced from Flue Gas. Oil \& Gas Journal, 130-136, November.

Baltus, R.E, Counce, R.M., Culbertson, B.H., Luo, H., DePaoli, D.W., Dai, S. and Duckworth, D.C. (2005) Examination of the Potential of Ionic Liquids for Gas Separations. Separation Science and Technology, 40, 525-541.

Barchas, R. and Davis, R. (1992) The Kerr-McGee/ABB Lummus Crest Technology for the Recovery of $\mathrm{CO}_{2}$ from Stack Gases. Energy Convers. Mgmt, 33,5-8, 333-340.

Bozzuto, C., Scheffknecht, G. and Fouilloux, J.P. (2001) Clean Power Generation Technologies Utilising Solid Fuels. Presentation to World Energy Council, 18th Congress, Buenos Aries, October.

Chakma, A. (1995) An Energy Efficient Mixed Solvent for the Separation of $\mathrm{CO}_{2}$. Energy Convers. Mgmt., 36, 6-9, 427-430.

Chakma, A. and Tontiwachwuthikul, P. (1999) Designer Solvents for Energy Efficient $\mathrm{CO}_{2}$ Separation from Flue Gas Streams. Greenhouse Gas Control Technologies. Riemer, P., Eliasson, B., Wokaun, A. (eds.), Elsevier Science, Ltd., Kidlington, United Kingdom, 35-42.
Chakravarty, S., Gupta, A. and Hunek, B. (2001) Advanced Technology for the Capture of Carbon Dioxide from Flue Gases. Paper presented at First National Conference on Carbon Sequestration, Washington DS, May 15-17.

Chapel, D., Ernst, J. and Mariz, C. (1999) Recovery of $\mathrm{CO}_{2}$ from Flue Gases: Commercial Trends. Paper No. 340 at Canadian Society of Chemical Engineers, Saskatoon, Canada.

Chen, H., Kovvali, A.S., Majumdar, S. and Sirkar, K.K. (1999) Selective $\mathrm{CO}_{2}$ Separation from $\mathrm{CO}_{2}-\mathrm{N}_{2}$ Mixtures by Immobilised Carbonate-Glycerol Membranes. Ind. Eng. Chem., 38, 34893498.

Chinn, D., Choi, G.N., Chu, R. and Degen, B. (2004) Cost Efficient Amine Plant Design for Post Combustion $\mathrm{CO}_{2}$ Capture from Power Plant Flue Gas. Paper presented at GHGT-7, Vancouver.

Cullinane, J.T. and Rochelle, G.T. (2002) Carbon Dioxide Absorption with Aqueous Potassium Carbonate Promoted by Piperazine, Greenhouse Gas Control Technologies, Vol. II, J. Gale, Y. Kaya, Elsevier Science, Ltd., Kidlington, United Kingdom, 1603-1606.

EIS (2000) Final Environmental Impact Statement for the JEA Circulating Fluidized Bed Combustor Project, US Department of Energy, June.

Erga, O., Juliussen, O. and Lidal, H. (1995) Carbon Dioxide Recovery by Means of Aqueous Amins. Energy. Convers. Mgmt., 36, 6-9, 387-392.

Feron, P.H.M. (1992) Carbon Dioxide Capture: The Characterisation of Gas Separation/Removal Membrane Systems Applied to the Treatment of Flue Gases Arising from Power Plant Generation Using Fossiel Fuel. IEA/92/08, IEA Greenhouse Gas R\&D programme, Cheltenham, United Kingdom.

Feron, P.H.M. (1994) Membranes for Carbon Dioxide Recovery from Power Plants. In: Carbon Dioxide Chemistry: Environmental Issues. Paul, J., Pradier, C.M. (eds.), The Royal Society of Chemistry, Cambridge, United Kingdom, 236-249.

Feron, P.H.M. and N.A.M. ten Asbroek (2004) New Solvents Based on Amino-Acid Salts for $\mathrm{CO}_{2}$ Capture from Flue Gases. Paper presented at GHGT-7, Vancouver.

Herzog, H., Golomb, D. and Zemba, S. (1991) Feasibility, Modeling and Economics of Sequestering Power Plant $\mathrm{CO}_{2}$ Emissions in the Deep Ocean. Environmental Progress, 10, 1, 6474.

IEA GHG R\&D Programme (2004) Improvement in Power Generation with Post-Combustion Capture of $\mathrm{CO}_{2}$. Report number PH4/33.

IFRF Combustion File 87.

Kovvali, A.S. and Sirkar, K.K. (2001) Dendrimer Liquid Membranes: $\mathrm{CO}_{2}$ Separation from Gas Mixtures. Ind. Eng. Chem., 40, 2502-2511.

Leites, I.L. (1998) The Thermodynamics of $\mathrm{CO}_{2}$ Solubility in Mixtures Monoethanolamine with Organic Solvents and Water and Commercial Experience of Energy Saving Gas Purification Technology. Energy Convers Mgmt., 39, 1665-1674.

Leites, I.L., Sama, D.A. and Lior, N. (2003) The Theory and Practice of Energy Saving in the Chemical Industry: Some Methods for Reducing Thermodynamic Irreversibility in Chemical Technology Processes. Energy, 28, 1, 55-97.

Mano, H., Kazama, S. and Haraya, K. (2003) Development of $\mathrm{CO}_{2}$ Separation Membranes (1) Polymer Membrane, In Greenhouse Gas Control Technologies. J. Gale and Y. Kaya (eds.), Elsevier Science, Ltd., Kidlington, United Kingdom, 1551-1554.

Marchetti, M.M, Czarnecki, T.S., Semedard, J.C., Lemasle, J.M. and Devroe, S. (2003) Alstom's Large CFB's and Results. 17th International Conference on Fluidised Bed Combustion, Jacksonville Florida USA, 18th to 21st May. 
McMullan, J. (2004) Fossil Fuel Power Generation: State of the Art. Report prepared by PowerClean R, D\&D Thematic Network, European Commission Contract No. ENK5-CT-2002-20625, July.

Mimura, T., Shimojo, S., Suda, T., Iijima, M. and Mitsuoka, S. (1995) Research and Development on Energy Saving Technology for Flue Gas Carbon Dioxide Recovery and Steam System in Power Plant. Energy Convers. Mgmt., 36, 6-9, 397-400.

Mimura, T., Simayoshi, H., Suda, T., Iijima, M. and Mitsuoka, S. (1997) Development of Energy Saving Technology for Flue Gas Carbon Dioxide Recovery in Power Plant by Chemical Absorption Method and Steam System. Energy Convers. Mgmt., 38, S57-S62.

Mimura, T., Satsumi, S., Iijima, M. and Mitsuoka, S. (1999) Development on Energy Saving Technology for Flue Gas Carbon Dioxide Recovery by the Chemical Absorption Method and Steam System in Power Plant, Greenhouse Gas Control Technologies. Riemer, P., Eliasson, B., Wokaun, A. (eds.), Elsevier Science, Ltd., Kidlington, United Kingdom, 71-76.

Mimura, T.K. Matsumoto, Iijima, M. and Mitsuoka, S. (2001) Development and Application of Flue Gas Carbon Dioxide Recovery Technology. Proceedings of the Fifth International Conference on Greenhouse Gas Control Technologies,Williams, D. et al. (eds), CSIRO publishing, Australia, 138-142.

Nsakala, Y.N., Marion, J., Bozzuto, C., Liljedahl, G., Palkes, M., Vogel, D., Gupta, J.C., Guha, M., Johnson, H. and Plasynski, S. (2001) Engineering Feasibility of $\mathrm{CO}_{2}$ Capture on an Existing US Coal-Fired Power Plant. Paper presented at First National Conference on Carbon Sequestration, Washington DS, May 15-17.

Okabe, K., Matsumija, N., Mano, H. and Teramoto, M. (2003) Development of $\mathrm{CO}_{2}$ Separation Membranes (1) Facilitated transport membrane, In Greenhouse Gas Control Technologies.
Gale, J. and Kaya, Y. (eds.), Elsevier Science, Ltd., Kidlington, United Kingdom, 1555-1558.

Quinn, R. and Laciak, D.V. (1997) Polyelectrolyte Membranes for Acid Gas Separations. Journal of Membrane Science, 131, 4960.

Sander, M.T. and Mariz, C.L. (1992) The Fluor Daniel ${ }^{\circledR}$ Econamine ${ }^{\mathrm{TM}}$ FG Process: Past Experience and Present Day Focus. Energy Convers. Mgmt, 33, 5-8, 341-348.

Stamatelopoulos, G., Scheffknecht, G. and Sadlon, E.S. (2003) Supercritical Boilers and Powerplants: Experience and Perspectives, Presented at PowerGen Europe 2003, Dusseldorf, Germany.

Teramoto, M., Nakai, K., Ohnishi, N., Huang, Q., Watari, T. and Matsuyama, H. (1996) Facilitated Transport of Carbon Dioxide through Supported Liquid Membranes of Aqueous Amine Solutions. Ind. Eng. Chem., 35, 538-545.

Van der Sluijs, J.P., Hendriks, C.A. and Blok, K. (1992) Feasibility of Polymer Membranes for Carbon Dioxide Recovery from Flue Gases. Energy Convers. Mgmt., 33, 5-8, 429-436.

Yamamoto, K., Kajigaya, I. and Umaki, H. (2003) Operational Experience of USC Steam Condition Plant and PFBC Combined Cycle System with Material Performance, Materials at High Temperatures, Volume 20, Number 1.

Zheng, X.Y., Diao, Y.F., He, B.S., Chen, C.H., Xu, X.C. and Feng, W. (2002) Carbon Dioxide Recovery from Flue Gases by Ammonia Scrubbing. Proceedings of Papers for Sixth International Conference on Greenhouse Gas Control Technologies, Kyoto, Japan, Oct. 1, Session No. I4-5.

Final manuscript received in May 2005 